\title{
El sitio fortificado del Castelinho (Felgar, Torre de Moncorvo, Portugal). Estudio preliminar de su diacronía y las plaquetas de piedra con grabados de la Edad del Hierro
}

\author{
The Fortified Settlement of Castelinho (Felgar, Torre de Moncorvo, \\ Portugal). First Approach to its Diachrony and the Iron Age Engraved \\ Stone Plaquettes
}

\author{
Filipe Santos*, José Sastre*, Sofia Soares de Figueiredo*, Fábio Rocha** \\ Eulália PinheIro**, Rodrigo Dias**
}

\begin{abstract}
* Arqueólogos, ACE. Coordinadores, respectivamente, del Estudio Etno-Arqueológico de Cilhades, Estudio sobre la Edad del Hierro del Valle del Sabor, Estudio de Arte Rupestre de Valle del Sabor. santos.philipe@gmail.com, josesastreb@hotmail.com, sofia.csf@gmail.com

** Arqueólogos, ACE. fabioricardorocha@gmail.com, eulaliapinheiro@gmail.com, rrsand@gmail.com
\end{abstract}

Recibido: 17-04-2012

Aceptado: 20-06-2012

\begin{abstract}
RESUMEN
Se presentan los resultados de la excavación arqueológica llevada a cabo en el sitio fortificado de la Edad del Hierro de Castelinho. La excepcionalidad del lugar, representada por las estructuras que posee y el extraordinario conjunto de plaquetas de piedra con grabados recientemente descubierto, ha tornado difícil su caracterización dentro del conjunto de la Edad del Hierro. Por las particularidades que el sitio presenta, situado en altura y con un amplio dominio visual, dotado de un imponente "sistema defensivo" con fosos y murallas asociados, podría considerarse como un castro en el sentido clásico del término. Tras un año de trabajos en esta importante estación arqueológica transmontana, se ofrecen en este artículo las primeras hipótesis en relación a su evolución diacrónica y la colección excepcional de arte mueble.
\end{abstract}

Palabras Clave: Edad del Hierro. Castro. Plaquetas de piedra con grabados. Fosos. Murallas. Trás-os-Montes. Portugal.

\begin{abstract}
In this text we present the results of the first archeological intervention in the Iron Age site of Castelinho. The uniqueness of the site, demonstrated by the presence of structures as well as an impressive assemblage of engraved stone plaquettes, has made the site difficult to characterize considering the regional context. The site, situated on a high point with commanding view of the surrounding area and enclosed by a massive "defensive system" of ditches and walls, could be considered as a Hillfort (castro) in the classic sense of the word. After a year of archaeological work in this important site we will address here several hypotheses in connection to the diachronic evolution of the hillfort, and the exceptional collection of portable art unearthed.
\end{abstract}

KeY words: Iron Age. Castro. Engraved Stone Plaquettes. Ditches. Walls. Trás-os-Montes. Portugal.

Sumario: 1. Introducción. 2. Localización y marco geográfico. 3. Contextualización del poblamiento de la Edad del Hierro en Trás-os-Montes. 4. El yacimiento del Castelinho. 5. La evolución diacrónica. Estructuras arqueológicas documentadas y su estratigrafía. 6. Las plaquetas de piedra con grabados. 


\section{Introducción}

El Castelinho es un yacimiento fortificado de la Segunda Edad del Hierro de la región de Trás-osMontes, con una particular relevancia a tenor de los materiales recientemente descubiertos en la excavación que se viene llevando a cabo desde inicios de 2011 (Fig. 1). Salvo intervenciones arqueológicas muy puntuales en yacimientos de amplia secuencia -desde el Calcolítico hasta época medieval (Rodrigues y Rebanda 1995: 55)- como el castro de Palheiros (Murça) (Sanches 2003: 120), hasta la fecha son muy pocos los trabajos realizados de manera efectiva y sistemática en la región.

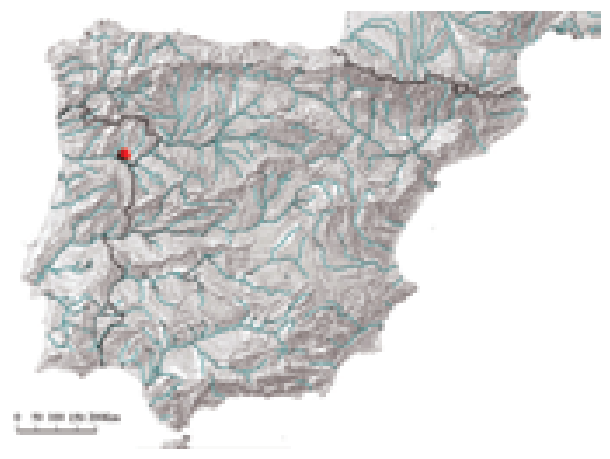

Figura 1.- Localización del Castelinho en la Península Ibérica.

El Castelinho ha sido referido en la bibliografía arqueológica de la región con relativa asiduidad. Recientemente fue incluido en el inventario de las estaciones arqueológicas elaborada por Sande Lemos (1993: 364), al realizar un estudio sobre el poblamiento romano del Trás-os-Montes Oriental. Este mismo investigador le otorga una cronología de la Edad del Hierro, clasificándolo, dentro de la tipología que llevó a cabo para estos poblados, como un castro de tipo D, esto es, sitios en lugares elevados en forma de espigón, dominando los cursos de agua y situados en valles o en bordes de meseta, pero siempre próximos a ríos o arroyos.

Con respecto a Castelinho, teniendo en cuenta la topografía del yacimiento, las construcciones relacionadas con su sistema defensivo (fosos, muralla $\mathrm{y}$ torreones) y los materiales hallados, podemos atribuirlo sin duda a la designación clásica de castro. Pero al mismo tiempo debemos tener presente que esa denominación no puede ser tajante, como recogen las actuales líneas de investigación. Estos sitios, constituidos en auténticos monumentos en el paisaje, son al mismo tiempo la expresión visual de una comunidad que reclama sus derechos sobre el territorio circundante (Esparza Arroyo 2011: 12). La intervención arqueológica que en este sitio se viene llevando a cabo desde marzo de 2011 se enmarca dentro de las medidas previstas para un amplio conjunto de estaciones arqueológicas directamente afectadas por la construcción de un embalse en relación al Aprovechamiento Hidroeléctrico del Baixo Sabor ${ }^{1}$ (Escalão de Montante).

\section{Localización y marco geográfico}

El yacimiento arqueológico de Castelinho es parte integrante de Cilhades, en la margen derecha del río Sabor y correspondiente a la freguesia de Felgar (concelho de Torre de Moncorvo, distrito de Bragança), en la región portuguesa de Trás-os-Montes. Sus coordenadas geográficas son: $\mathrm{X}=97404,00 ; \mathrm{Y}$ $=175408.00$. El sitio aparece recogido en la Carta Militar de Portugal, escala 1:25 000, Hoja ${ }^{\circ} 119$ y ocupa la zona alta de un espigón de substrato esquistoso, sobre el valle del río Sabor, bien destacado en el paisaje y dominando visualmente una extensa zona (Fig. 2).
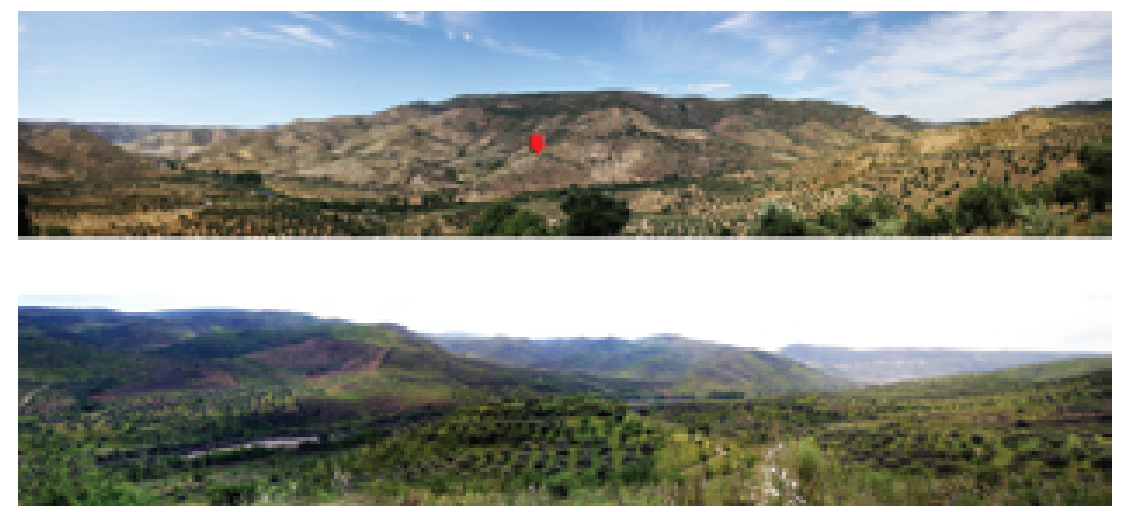

Figura 2.- Vista general del lugar de Cilhades desde el margen izquierdo del Rio Sabor. Vista sobre el espigón donde se localiza el yacimiento del Castelinho. 
De su entorno inmediato destacan sus propias vertientes y la zona de la Sierra de Bornes, con alturas cercanas a los $500 \mathrm{~m}$ de altitud. Las vertientes Sur, Oeste y Este son bastante acentuadas y funcionan como líneas de defensa naturales. La cota absoluta de esta pequeña elevación es de $212.5 \mathrm{~m}$. En términos generales el valle del Sabor, aunque se trata de un valle abierto, ofrece en esta zona un perfil en $\mathrm{V}$ bastante marcado. A nivel geológico abundan los esquistos, gravas y cuarcitas, prevaleciendo los litosuelos.

\section{Contextualización del poblamiento de la Edad del Hierro en Trás-os-Montes}

El castro se sitúa en la región portuguesa de Trásos-Montes Oriental, un área colindante con la provincia española de Zamora. Aunque esta región posee un importante poblamiento relacionado con la Edad del Hierro, faltan excavaciones sistemáticas que aporten una secuencia cronológica precisa sobre el origen y evolución de estos castros, ya que la mayoría de los trabajos realizados hasta la fecha se reducen a prospecciones arqueológicas (Esparza 1988; Sande Lemos 1993), o pequeños sondeos (Rodrigues y Rebanda 1995). Los trabajos que ahora se desarrollan en Castelinho y en Castelo dos Mouros (Vilarinho dos Galegos, Mogadouro), éste último bajo la dirección de Antonio P. Dinis, aportarán sin duda información relevante para la zona.

La región de Trás-os-Montes Oriental no difiere en demasía, desde el punto de vista geográfico, de las tierras occidentales de Zamora y el noroeste de Salamanca, teniendo como eje vertebrador el río Duero, del cual es importante afluente el Sabor. Podemos apreciar en la zona una importante densidad de poblados, especialmente en áreas como el valle del río Vilariça, afluente del Sabor, o en torno a los Arribes del Duero, siguiendo la frontera entre España y Portugal (Fig. 3). Algunos son de grandes dimensiones, como Nossa Senhora do Adeganha (Adeganha, Torre de Moncorvo), y otros más pequeños, como el que nos ocupa. Estos poblados se sitúan por lo general en zonas muy destacadas del paisaje, controlando el territorio y los recursos circundantes, fácilmente visibles por sus defensas, como el mencionado de Nossa Senhroa de Adeganha, con una muralla de grandes bloques de granito que recuerdan al salmantino de Yecla de Yeltes, superando los $2 \mathrm{~m}$ de altura conservada.

En cuanto a las propias características de los castros trasmontanos, destaca, como venimos refiriendo, la presencia de murallas de granito o esquisto, muchas de ellas de gran tamaño, como el Castelo de Marruça (Parada, Alfândega da Fé), con un lienzo magníficamente conservado de más de $3 \mathrm{~m}$ de altura y $2 \mathrm{~m}$ de anchura en alguna de sus zonas. Estas murallas, a falta de poder completar el estudio que actualmente estamos desarrollando sobre el poblamiento de la comarca, serian de dos tipos: las que rodearían la totalidad del recinto, como es el caso de Cigadonha (Carviçais, Torre de Moncorvo), o aquellas que protegerían tan sólo la parte más débil o accesible al castro, como Cerca dos Mouros (Talhas, Macedo de Cavaleiros).

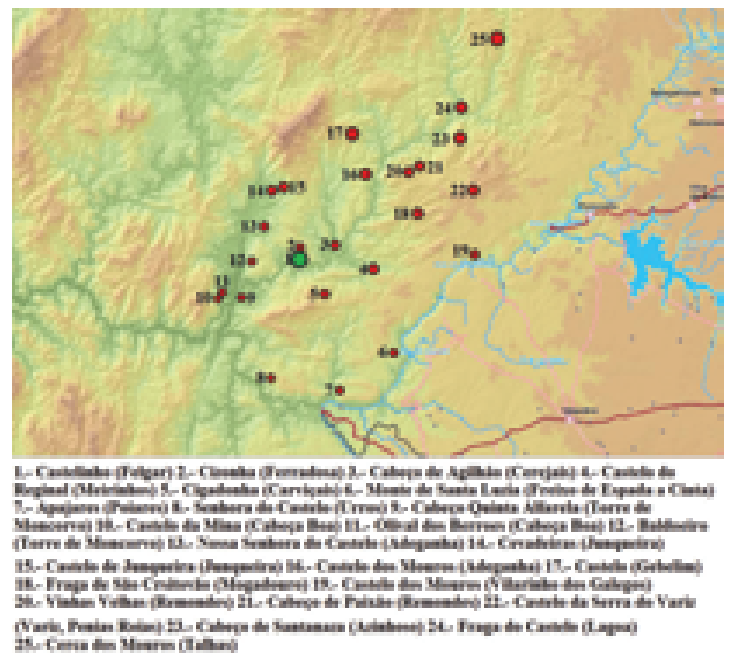

Figura 3.- Yacimientos de la Edad del Hierro en la zona del Baixo Sabor y su entorno más cercano.

Las murallas se acompañan en ocasiones de otros elementos defensivos como los campos de piedras hincadas; así lo hemos constatado en los ya mencionados de Castelo dos Mouros (Vilarinho dos Galegos) y Castelo do Marruça. No así en Castelinho, aunque no podamos descartar su presencia, dadas las intensas labores agrícolas que se han llevado a cabo en la zona y que podrían haber afectado al yacimiento. Estos campos de piedras siempre han sido controvertidos en cuanto a su utilidad como elementos defensivos para frenar el avance del enemigo hacia el poblado (Esparza Arroyo 2003 y Ruiz Zapatero 2003:18-19). Sin embargo, ante casos como el de Vilarinho dos Galegos, donde el campo de piedras hincadas se levantó utilizando cuarzos de colores blancos muy vivos, no desdeñaríamos la posibilidad de considerarlos, junto a murallas, torreones y fosos, como un elemento más monumental que propiamente defensivo (Ralston 2006). En la irlandesa isla de Aran nos encontramos con un caso interesante como es el del famoso Dun Aonghasa, con un inmenso y denso campo de piedras hincadas totalmente desproporcionado en relación al tamaño del sitio y de la propia isla (Cotter 2003: 103-107). 
Otro elemento característico son los fosos, y aunque muchos no han sido excavados y eso dificulta su interpretación, no ocurre así en Castelinho. En un principio no era perceptible la presencia de ningún tipo de foso, ya que en superficie no se observaba ninguna depresión, pero al ampliar la excavación al exterior del recinto amurallado se documentaron cuatro de ellos. Como ha señalado A. Esparza, mientras en Inglaterra e Irlanda se han venido realizando excavaciones en los fosos de los hillforts (Collis 2010), en nuestros castros nunca se ha considerado prioritaria tal actuación, y podría producirse alguna sorpresa (Esparza 2011). Por esto nos encontramos ante un problema a la hora de encontrar paralelos entre los fosos de las zonas de Trás-os-Montes occidental y Zamora, donde las excavaciones no se han preocupado por este tipo de estructuras. Un caso significativo es el ya citado de Castelos dos Mouros (Vilarinho dos Galegos), donde mencionábamos la presencia de un campo de piedras hincadas, tras el que se encontraría un foso de gran anchura y profundidad. Todo este conjunto de posibles elementos defensivos le otorgan una gran monumentalidad a ese yacimiento.

Todavía nos hallamos en una fase preliminar en el estudio del poblamiento de la Edad del Hierro en la región. Algunos de los sitios que históricamente han sido relacionados con la época no lo parecen, como avalan los materiales recuperados en prospección. Por eso, en este trabajo queremos aprovechar la posibilidad de realizar un análisis más minucioso de estos lugares, desechando todos aquellos que no ofrezcan indicios reales de su correspondencia a este periodo para, de esta forma, situar el yacimiento de Castelinho en su contexto preciso.

\section{El yacimiento del Castelinho}

Castelinho es un poblado fortificado de contorno ovalado $(100 \times 60 \mathrm{~m})$ y orientación Noroeste-Sureste. El espacio intramuros abarca $4785 \mathrm{~m}^{2}$, englobando parte del talud artificial de la zona Sur del recinto.

La muralla, más ancha en la base y con un perímetro de $360 \mathrm{~m}$ que rodea la práctica totalidad del poblado, a excepción de la plataforma norte (la zona de más fácil acceso al interior del recinto, donde la muralla se presenta escalonada, con una longitud de $11 \mathrm{~m}$ ) se conserva bien en algunos puntos (Fig. 5). La técnica constructiva parece uniforme, dos paramentos de mampostería en seco bien ajustado, con esquistos y relleno de piedras. Dos torreones de planta subcircular se erigen junto a la muralla, en los extremos norte -la zona más expuesta- y sureste del recinto. El primero, más grande, es el resultado de una profunda remodelación del sistema defensivo, levantándose sobre la muralla primitiva del castro.

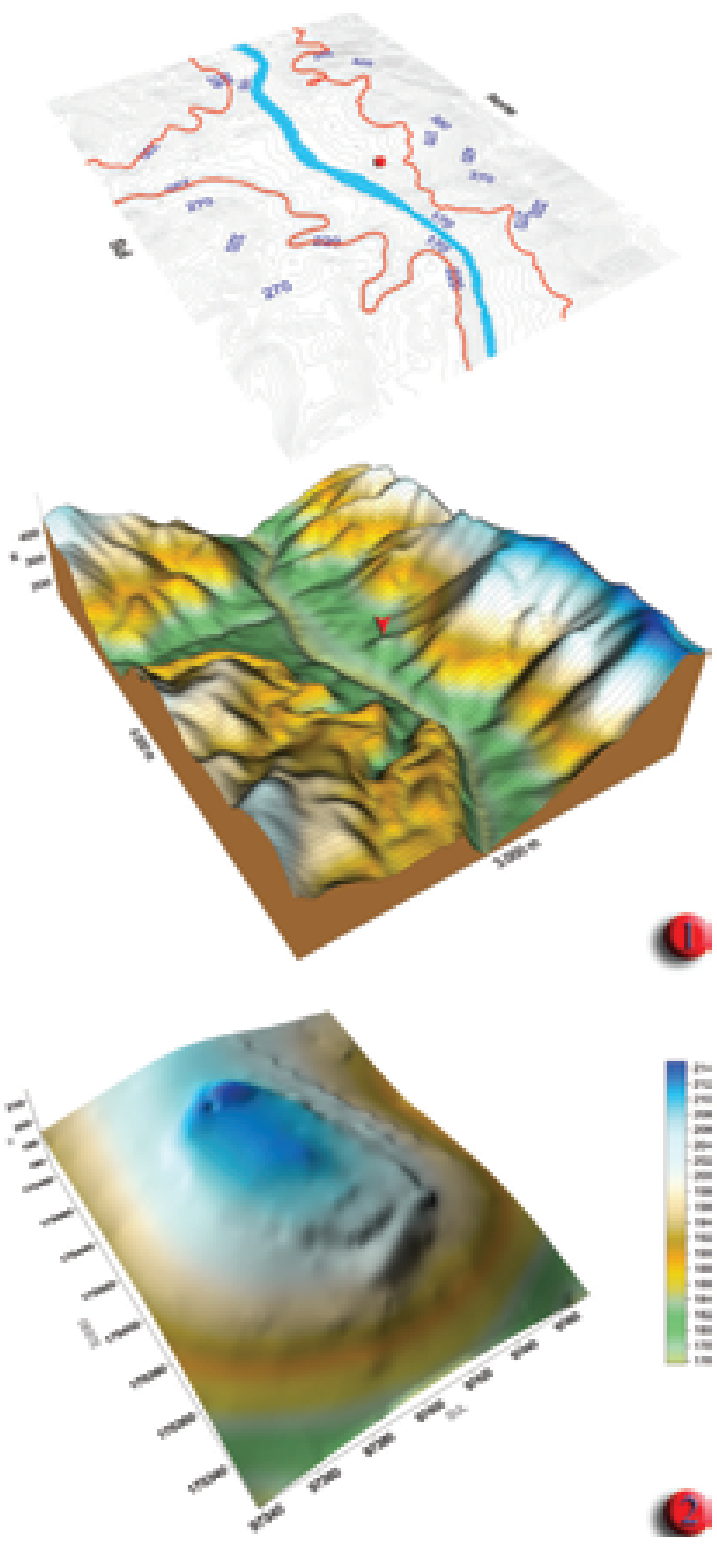

Figura 4.- Planta y representación en $3 \mathrm{D}$ del área circundante del Castelinho (1). Recreación en 3D del Castelinho a partir del diseño topográfico inicial (2).

Esta primera línea defensiva, que nos retrotrae a un primer momento de monumentalización del sitio, tiene menores dimensiones y parece describir dos vueltas en torno al centro del espigón, desenvolviéndose en espiral y en relación con 3 de los 4 fosos que hemos podido identificar hasta el momento en la excavación de la plataforma Norte (ver al respecto los tipos de entradas documentadas en los castros de la Alta Extremadura, Bonnaud 2005: 235). La colmatación de la cuarta y última línea de foso, que acaba por cortar dos de las anteriores, parece relacionarse 


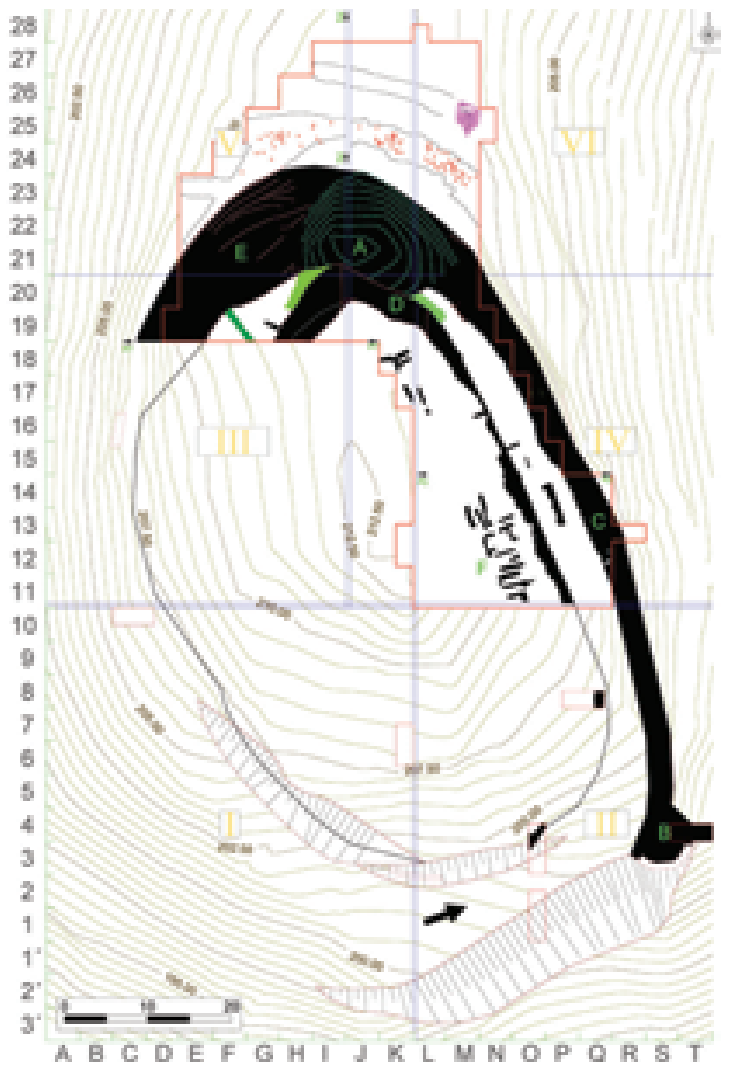

Figura 5.- Planta general del Castelinho (hasta el final de la primera fase de excavación). A: Torreón Norte, B: Torreón Sur, C: Muralla, D: Muralla, E: Muralla escalonada, F: Horreum. con el último momento de ocupación del sitio, ya en época romana. Esta colmatación habría tenido lugar en un momento inmediatamente posterior a la edificación de la muralla escalonada y del gran torreón, pero aún dentro de la Edad del Hierro.

Las estructuras internas del poblado aparentan cierta diversidad, pero poco más podemos decir de los sondeos realizados hasta el momento. Son muros de dimensiones variables y distinta tipología, construidos con piedra de esquisto en seco, mediante la superposición regular de lajas de pequeño y mediano tamaño, usando granito y cuarcita de forma ocasional. La regularidad de los muros sugiere un trazado ortogonal, y de momento no tenemos evidencias de construcciones de planta circular. Parece bastante probable el recurso a materiales perecederos para construir en altura pues, salvo excepciones, no se han documentado niveles de derrumbe que puedan vincularse a estos muros. Por último hay que mencionar la presencia de un conjunto de pequeños muros de esquisto que discurren en paralelo, a distancias regulares y ocasionalmente unidos con lajas transversales. Se localizan al oeste del corredor, junto a la muralla por su cara interna. Se encuentran muy deteriorados pero, a tenor de sus características técnicas y arquitectónicas, parecen corresponder a una zona de almacenaje, probablemente relacionada con graneros (horrea). Teniendo en cuenta los materiales hallados (algunos fragmentos cerámicos y dos monedas de Augusto), pensamos que corresponderían a la última gran fase de ocupación del lugar, ya en época romana (Fig. 6)

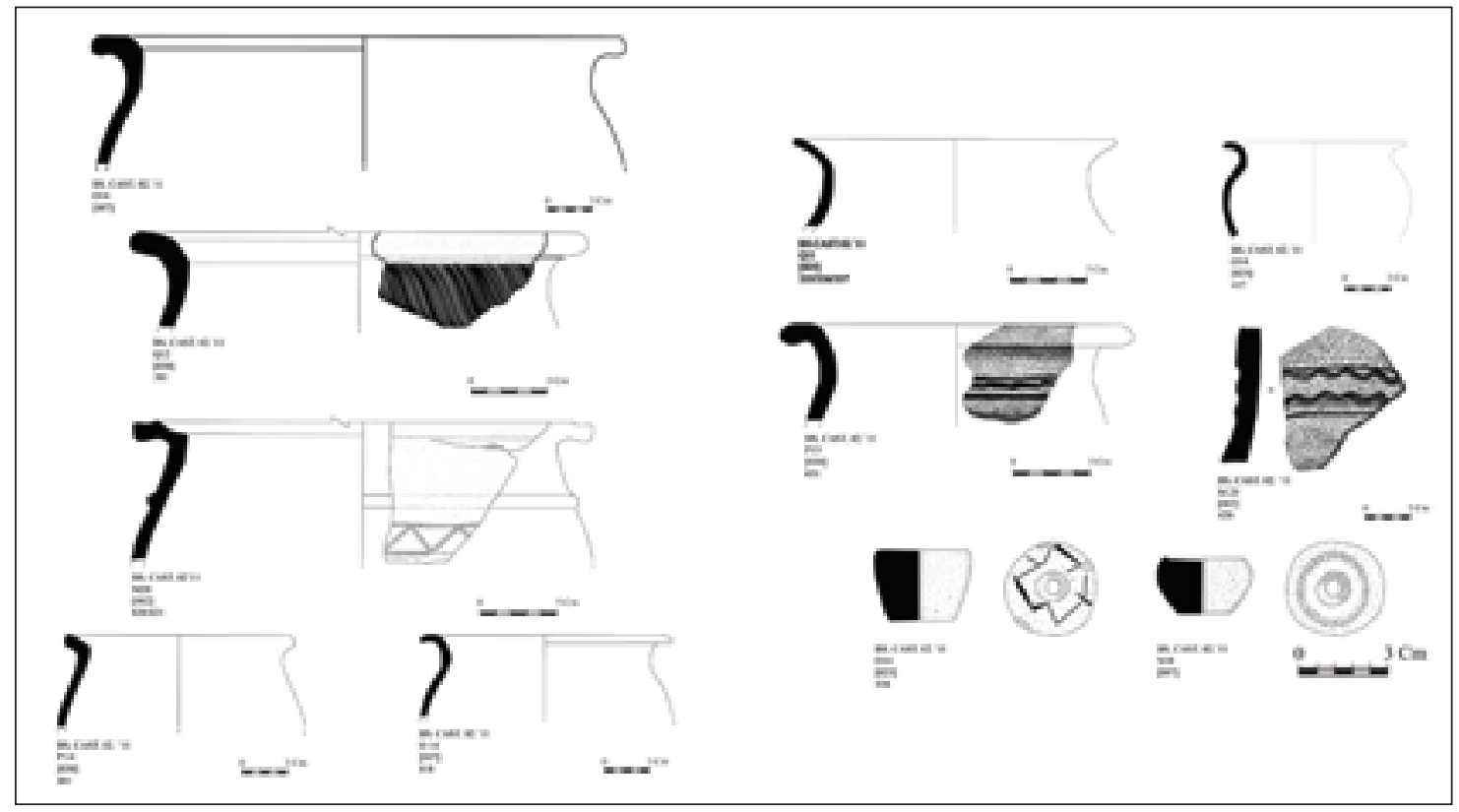

Figura 6.- Materiales cerámicos procedentes del Castelinho. 
La cerámica hallada en el yacimiento es poco expresiva. Básicamente se trata de fragmentos lisos de tamaño medio y grande que se relacionarían con piezas de almacenaje de formas globulares y ovoides. Unas pocas están decoradas con motivos incisos. No obstante un primer análisis nos ha permitido diferenciar varios grupos, confirmando lo que las propias estructuras arqueológicas ya nos venían mostrando: un primer conjunto, residual pero bien identificado a nivel estratigráfico, fechado entre finales del siglo VI a.C. y los inicios del siglo V. a.C ${ }^{2}$. Un segundo lote, el más abundante, encuadrable a finales de la Edad del Hierro (s. III), y cerámica común romana.

Aparte de los elementos cerámicos, se encontraron un buen número de restos faunísticos, que constituyen, como es obvio, una importante fuente de información sobre los hábitos alimentarios y las especies consumidas por la comunidad que ocupó el lugar. En cuanto a los materiales líticos, además de algunos pulidores, se han documentado percutores, todos en cuarzo. También sobresale la presencia de molinos manuales, destacando por encima de todos los molinos circulares.

Los objetos metálicos tienen una especial relevancia por la particularidad de algunas piezas y su potencial datación. Se conocen varias fíbulas anulares hispánicas, en omega, dos de tipo transmontano y una zoomorfa de caballito, bien encuadrable en los siglos II-I a.C. Entre los objetos de hierro, varias hojas de hoz y piezas diversas de armamento (Fig. 7) Por último, podemos destacar una mo- neda acuñada en Castulo (Jaén), datable ${ }^{3}$ a mediados del siglo II a.C., representando una cabeza humana de perfil, que parece llevar una diadema (anverso), y una esfinge alada (reverso) (Fig. 11). Un elemento muy destacado relacionado con la estatuaria es el de una cabeza antropomorfa bastante realista, realizada en granito (Fig. 8). Se ha datado en la II Edad del Hierro (Santos y Ladra 2011: 10), aunque siempre con sus lógicas reservas.
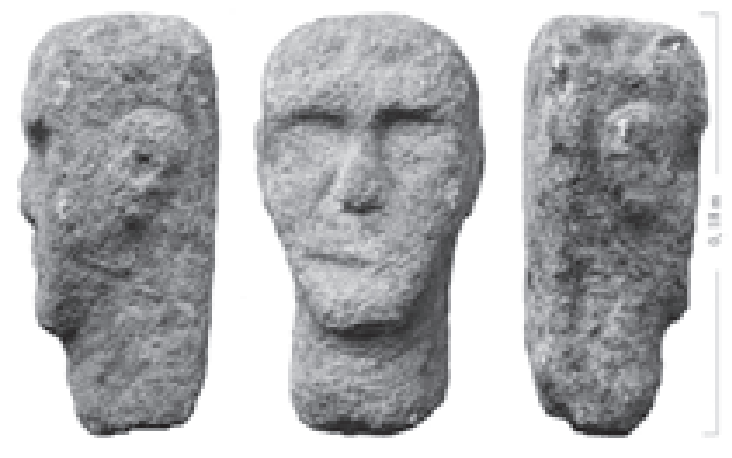

Figura 8.- Cabeza antropomorfa del Castelinho.

Pero la excepcionalidad del sitio descansa sin duda en la colección de arte mueble localizada hasta la fecha, constituida por más de 140 lajas grabadas con motivos figurativos diversos, la mayor parte de las cuales se documentaron en el interior de uno de los fosos, como veremos más adelante.

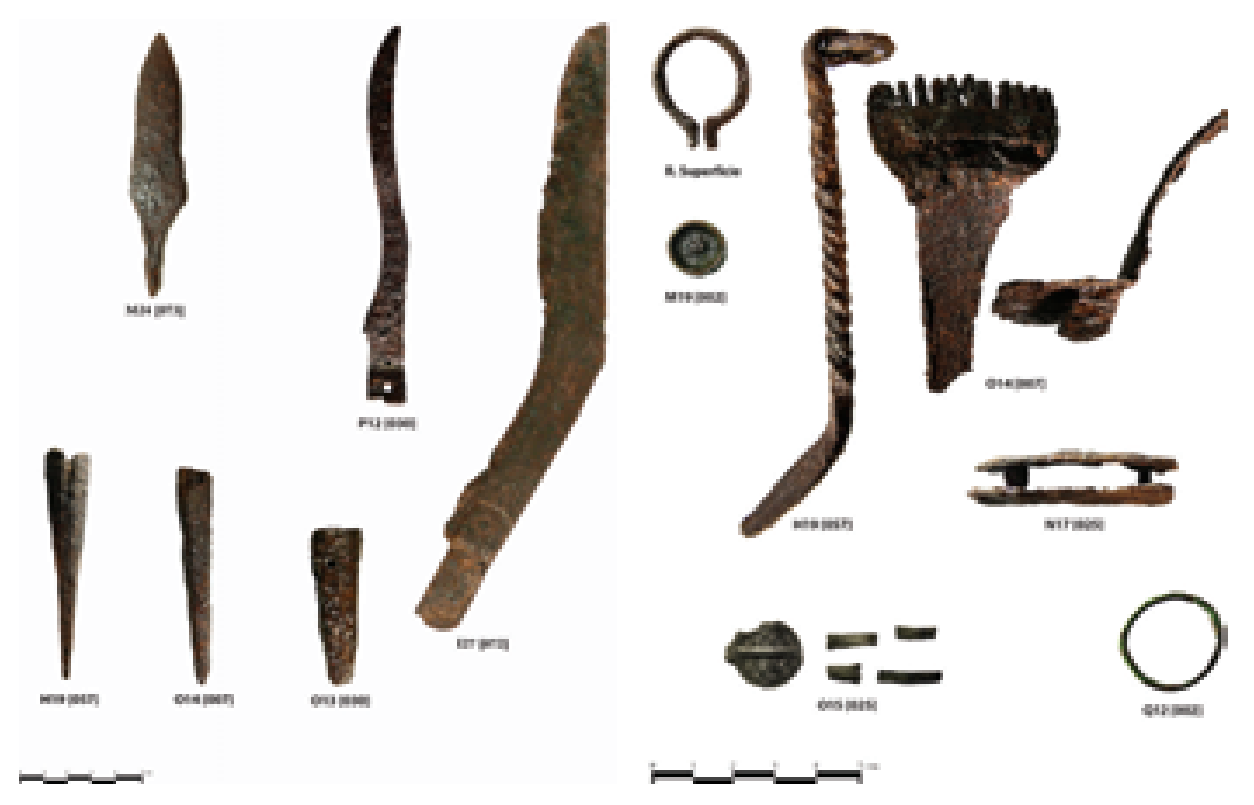

Figura 7.- Objetos metálicos provenientes del Castelinho. Elementos de armamento a la izquierda. 


\section{La evolución diacrónica. Estructuras arqueo- lógicas documentadas y su estratigrafía}

Abordaremos brevemente las estructuras que han sido identificadas en el transcurso de la intervención arqueológica y su correspondencia estratigráfica. En relación a esta secuencia juzgamos posible establecer, grosso modo, tres grandes momentos de ocupación.

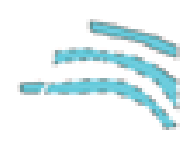

\section{Fase I}

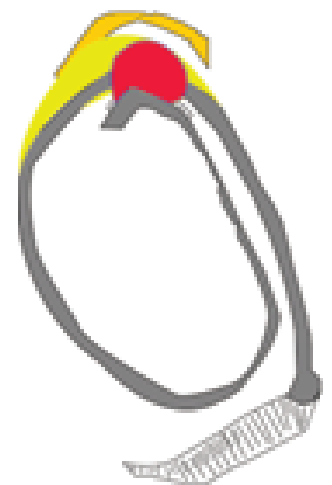

Fase IIA

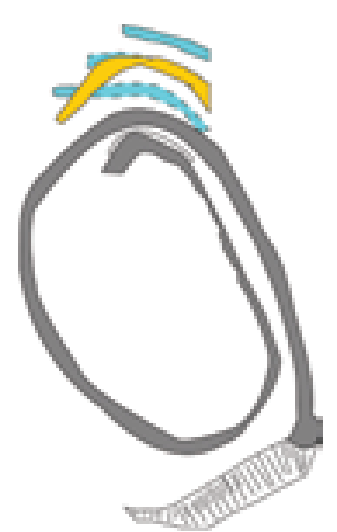

Fase II

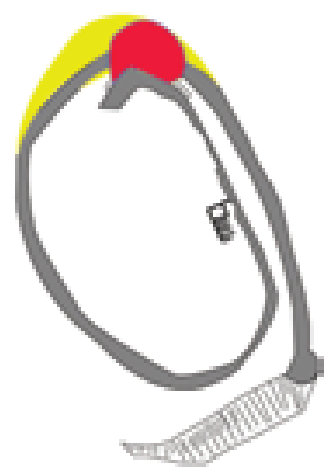

Fase III

Figura 9.- Planta de las diferentes fases del Castelinho.

\subsection{Las estructuras arqueológicas de la Fase I}

Hasta la fecha no existen estructuras arqueológicas asignables con rotundidad al primer momento de ocupación del Castelinho. Nos debemos ceñir únicamente a un nivel de tierras carbonosas en el cual se han localizado abundantes semillas carbonizadas, asociadas a nódulos de barro de revestimiento y unas pocas cerámicas. Ha sido precisamente el análisis de los mencionados fragmentos, muy dis-

tintos del material recogido en el yacimiento, lo que nos ha permitido identificar una fase inicial que podría llevarse a un momento impreciso de finales del siglo VI a.C. e inicios del V a.C. Restos que podrían relacionarse con una estructura de almacenamiento hecha en arcilla y materiales perecederos, muy destruida, seguramente por acción del fuego. Este momento se corresponde con los fosos 1, 3 y 4. Esta hipótesis nos lleva a pensar que en esta fase el Castelinho no habría contado con una muralla, constituyéndose como un poblado abierto.

\subsection{Las estructuras arqueológicas de la Fase II}

No podemos obviar el aparente hiato temporal que existe entre la primera y la segunda ocupación del poblado. Pero tampoco disponemos, al menos de momento, de dataciones que puedan corroborar el hecho. Creemos que a esta segunda fase se podrían asociar dos momentos constructivos que implican una profunda remodelación del sistema defensivo. De una parte la construcción de la muralla, que se desarrolla en espiral en dirección al centro del poblado, al tiempo que delimita un pasillo o corredor entre el lienzo y la entrada Sur. Adquiere entonces el poblado su característica forma de planta ovala$\mathrm{da}$, con orientación $\mathrm{NO} / \mathrm{SE}$ y un espacio intramuros de aproximadamente $0,5 \mathrm{Ha}$.

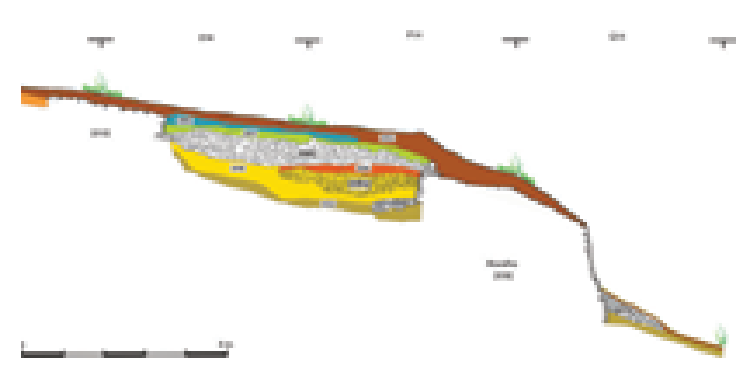

Figura 10.- Castelinho, perfil estratigráfico 3. Detalle del nivel de preparación [032] donde se erigió la muralla y niveles de regularización [030] [030A] [026] relacionados con el corredor de circulación entre muros.

La muralla, de $4 \mathrm{~m}$ de ancho y algo mayor en la base, conserva un talud en la zona sur y un pequeño torreón, seguramente protegiendo el acceso al poblado. En este sector el lienzo descansa sobre un nivel de cimentación o regularización previo, con testimonios residuales de la primera fase de ocupación (Fig. 10). Se trata de un relleno formado por pequeñas lajas de esquisto y unas pocas concentraciones de cuarzos. Prácticamente estéril desde el punto de vista arqueológico, parece haber funcionado como 
un elemento de drenaje de la propia muralla, función con la que podrían estar relacionadas algunas concentraciones de cantos rodados. Una situación análoga fue valorada por Martin Höck (1977) en la excavación que llevó a cabo en el castro de São Juzenda, en Mirandela. Sobre este nivel se excavaron algunos depósitos que depararon abundantes restos cerámicos y metálicos, entre otros dos fíbulas de tipo transmontano, bien datadas en los siglos III-II a.C. (Ponte: 2006) y una moneda de Castulo (16080 a.C.) (Fig. 11).
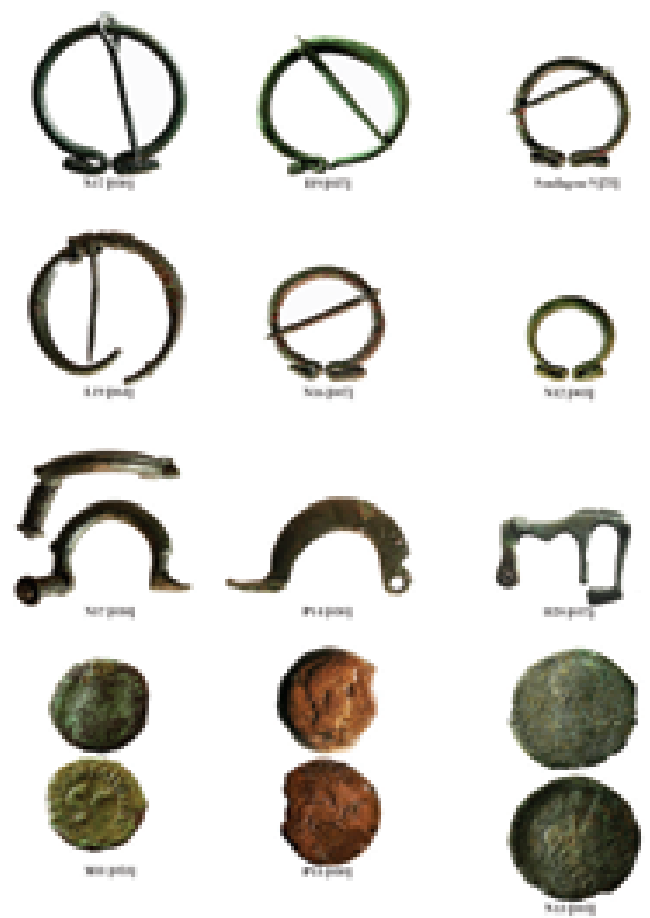

Figura 11.- Fíbulas y monedas recuperadas en la excavación arqueológica del Castelinho.
Se identificaron distintas estructuras que revelan la complejidad de esta segunda fase de ocupación; entre otras, un muro de piedra $(5 \times 0,80 \mathrm{~m})$ asociado a la muralla, dos rampas de acceso en la zona norte del recinto, más tarde amortizadas con la construcción del torreón, el denominado foso 2 , que termina por cortar los ya preexistentes relacionados con la primera fase de ocupación (fosos 3 y 4), una estructura de grandes dimensiones (11 m de ancho) asociada a la muralla escalonada -que en un momento impreciso se refuerza, camuflando parte de la muralla antigua- y el torreón Norte, que se levanta sobre otras construcciones previas (Figs. 12 y 13).

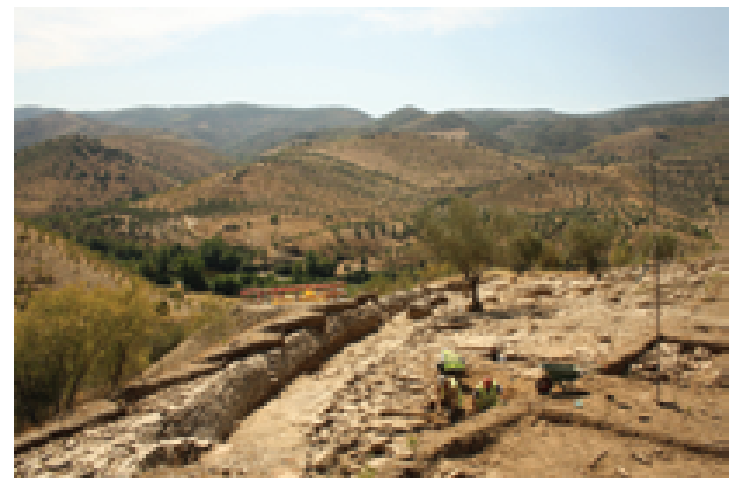

Figura 13.- En primer término, corredor entre muros y cara interna de la muralla.

\subsection{Las estructuras arqueológicas de la Fase III}

La última fase de la vida del castro es contemporánea de la conquista romana. Junto a la muralla de la Segunda Edad del Hierro se localizaron varias estructuras delimitadas por muros paralelos y equidistantes entre sí, entre las cuales pudimos identificar un edifico de orientación NO/SE seguramente des-

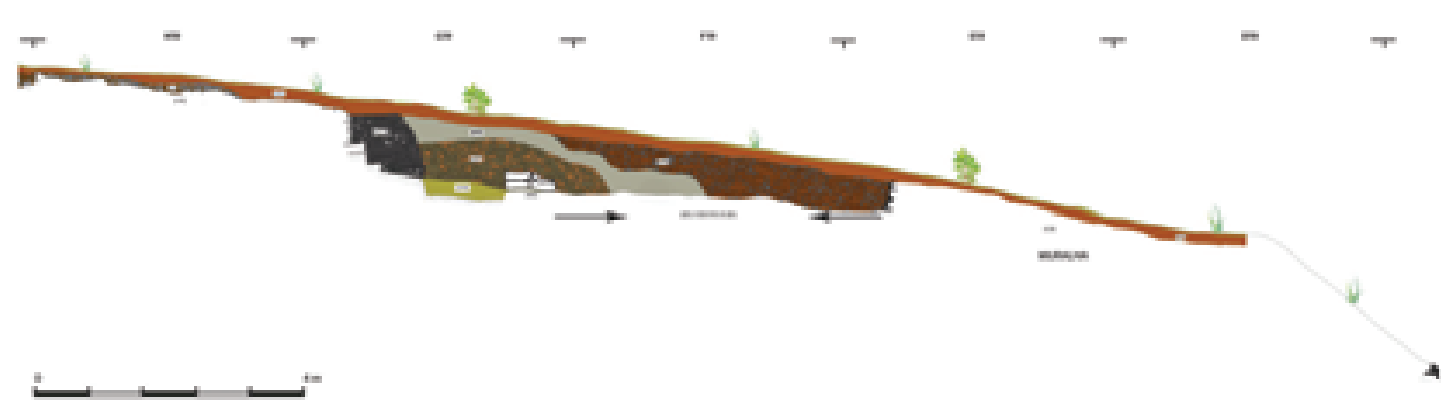

Figura 12.- Castelinho, perfil estratigráfico 7. Representación de algunas de las estructuras asociadas a la Fase II [066] y [077], y los depósitos [037] [057] y [065] que las colmatan. 
tinado a almacén de cereal (horreum), análogo a los ya conocidos en las estaciones romanas de Quinta da Fórnea (Belmonte) y Freiria (Cascais) (Salido 2003-2004: 468). Asociados a estas estructuras aparecieron fragmentos de cerámica común romana y dos monedas de época augustea de los años 7 a.C. y 30-20 a.C. La última es un As de cobre acuñado en Osca (Huesca). En su anverso presenta el texto "VRB", con la cabeza de Octavio, y a la derecha el texto "VICT". En el reverso se encuentra un jinete con lanza y el texto "OSCA". Este momento se corresponde con la colmatación y amortización del foso 2 , proceso durante el cual se vertieron más de un centenar de lajas grabadas con arte de la Edad del Hierro, así como una inscripción con caracteres latinos.

\subsection{La intervención en la plataforma Norte: fosos, materiales y estructuras asociadas}

A finales del mes de Octubre de 2011 comenzaron los trabajos en la zona externa del perímetro amurallado, en torno a una plataforma muy regular situada al Norte (Fig. 14).

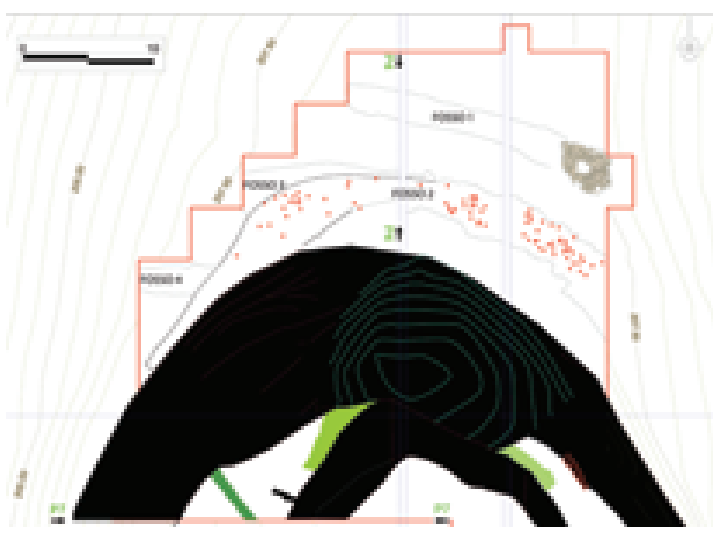

Figura 14.- Plano de excavación de la plataforma Norte: detalle de los fosos y estructuras asociadas, con localización de las plaquetas grabadas (puntos). La mayoría de las piezas proceden de los niveles de colmatación del Foso 2.

El objetivo era documentar la existencia de restos asociados a la ocupación protohistórica en su parte extramuros. Desde un principio barajamos la posibilidad de localizar en este sector una línea de fosos y el campo de piedras hincadas, como ocurre en Castelo dos Mouros (Vilarinho dos Galegos), sin descartar la existencia de estructuras habitacionales, lo cual no parece confirmarse por el momento. La limpieza de los niveles superficiales dejó al descubierto cuatro líneas de corte muy visibles que identificamos como fosos. Los denominados fosos 1 y 2 discurren en paralelo a la muralla, distanciados $4 \mathrm{~m}$ entre sí y con orientación Oeste/Este. Los fosos 3 y 4 parecen desarrollarse perpendicularmente a partir del segundo, hacia el oeste del área excavada. La excavación reveló claras semejanzas entre los niveles de relleno de los fosos 1,3 y 4, con una ausencia casi total de elementos pétreos y materiales arqueológicos; no así el foso 2, completamente heterogéneo y con muchos elementos pétreos asociados. Este acaba por cortar un tramo del Foso 4, en la zona Oeste, y otro del Foso 3, aprovechando en buena parte la zanja de fundación asociada a esta estructura primitiva. Sobre los niveles de colmatación del foso 1 se identificó una pequeña estructura semicircular con lajas dispuestas horizontalmente que podría corresponderse con una cámara de tipo sepulcral (Cachero 2008).

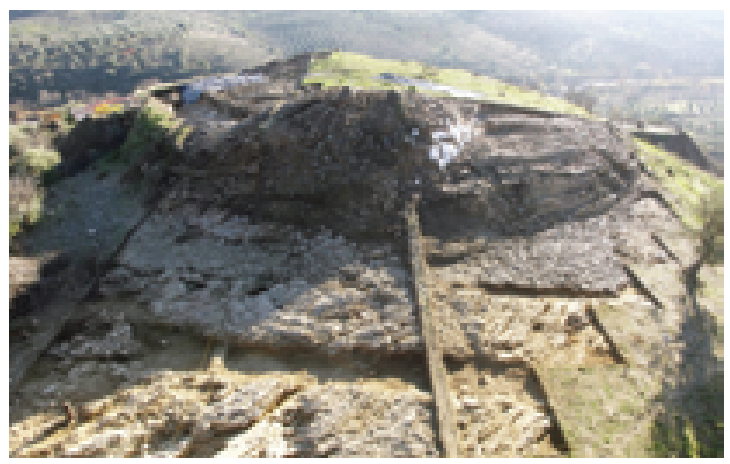

Figura 15.- Vista panorámica de la plataforma Norte del Castelinho. En primer plano: el Foso 1. Es visible un trozo de la muralla escalonada y del torreón Norte.

El primer foso fue detectado en una extensión de $16 \mathrm{~m}$ de área excavada. Tiene perfil en "U" y una profundidad media de $0,50 \mathrm{~m}$. Del interior se recogieron cinco fragmentos cerámicos y una pequeña placa de esquisto perforada. El segundo foso fue posteriormente cubierto con sucesivas camadas de piedra, tierra y sedimentos arenosos. La excepcionalidad del relleno descansa sobre todo en las cerca de 120 lajas grabadas, vertidas de forma aleatoria a lo largo de la estructura defensiva. Esta colmatación pretendía cerrar de manera intencionada el foso, lo que tal vez explique la escasez de otros materiales arqueológicos (Fig. 16). Así, durante el proceso de excavación se recogieron algunos restos de fauna, medio centenar de fragmentos cerámicos -semejantes a los procedentes del interior del poblado en los niveles correspondientes a la II Fase de ocupaciónalgunos fragmentos de molinos circulares y unos pocos percutores. En la base del foso se localizaron también tres dolabras en hierro (Fig. 17). 


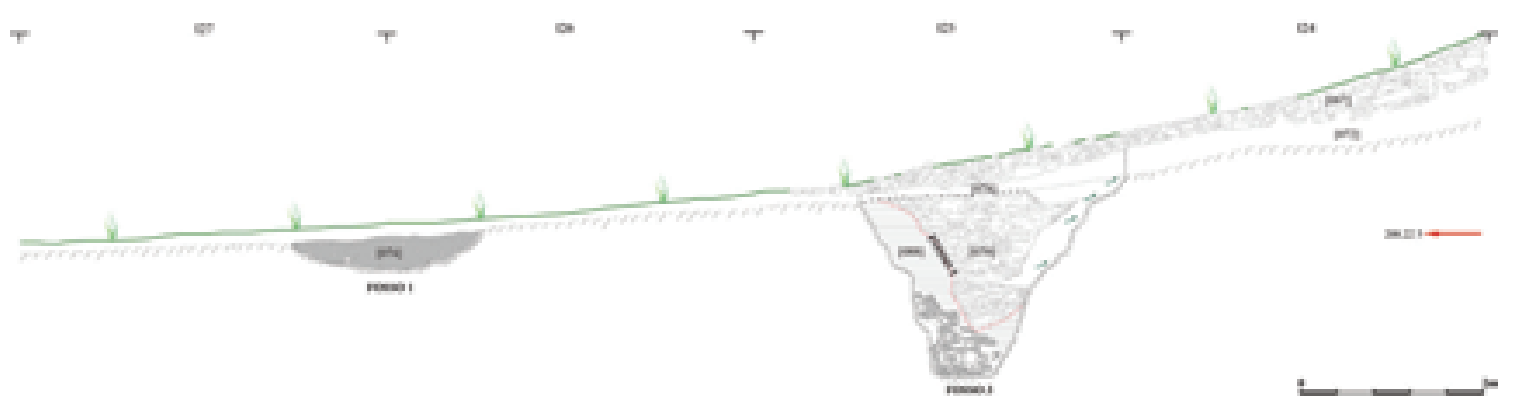

Figura 16.- Castelinho, perfil estratigráfico 4. Representación de los fosos 1,2 y 3 , y de los respectivos rellenos. Destaca el corte provocado por la abertura del Foso 2 y los niveles de colmatación del foso 3. La UE. [079], corresponde al cierre intencionado y rápido del Foso 2.En esta misma unidad fueron identificadas más de un centenar de lajas grabadas.

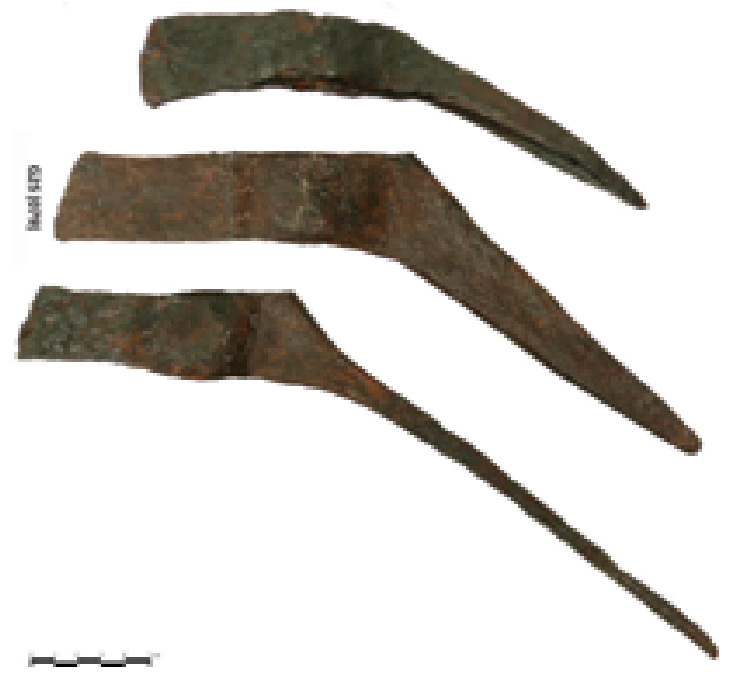

Figura 17.- Detalle de las dolabras recuperadas en el Foso 2.

En resumen, los trabajos que venimos desarrollando en la plataforma extramuros nos han permitido plantear tres momentos distintos en la evolución del asentamiento en este sector: (1) la construcción de tres líneas de foso paralelas entre sí, Fosos 1, 3 y 4 , (2) la construcción de una cuarta línea de foso, el denominado Foso 2, que al ser construido acaba por cortar los tramos y respectivos niveles de colmatación de los Fosos 3 y 4, aprovechando el desarrollo hacia el Este de la primitiva zanja asociada al Foso 3 , y (3) la colmatación del Foso 2 y el vertido de las lajas grabadas, en un momento que no podemos precisar pero que implica una acción rápida hasta cerrar completamente la estructura. El relleno intencionado del Foso 2 remite a una situación bien estudiada por J.D. Hill (1995a y 1995b) para los fosos de hillforts británicos en los que claramente las distintas partes de los fosos fueron deliberadamente colmatadas con el entierro de distintos elementos según las diferentes partes de los fosos. Todo ello presidido por un gran contenido simbólico como, sin duda alguna, sucedió en el caso del Castelhino.

La construcción de la posible estructura funeraria antes citada sobre los niveles de colmatación del Foso 1 podría estar asociada a la colmatación del Foso 2. Sabemos con certeza que una parte de la muralla escalonada del Castelinho se levanta sobre los límites de la línea de Foso 2 en el Oeste, lo que deberá corresponder al último de los tres grandes momentos edificativos que hemos documentado.

Dentro de las distintas fases propuestas para el Castelinho no es posible, a fecha de hoy, establecer una relación directa entre estas estructuras negativas y las distintas fases de ocupación. Creemos posible que las tres líneas de foso primitivas, Fosos 1, 3 y 4 podrían relacionarse con una primera monumentalización del yacimiento, al tiempo que se erige la muralla. Por otro lado, no es descabellado pensar que las tres líneas de foso primitivas estuvieran relacionadas con los materiales de la primera fase de ocupación del Castelinho, pudiendo situarse en torno al siglo $\mathrm{V}$ a.C. A comienzos de la segunda fase (IIA) parece tener lugar una profunda remodelación del sistema defensivo, que relacionamos fundamentalmente con el engrosamiento de la muralla en la zona norte del poblado al tiempo que se levanta el torreón Norte y se construye el Foso 2. Todas estas remodelaciones se habrían producido, muy posiblemente, entre inicios del siglo II a.C. y el I a.C., inmediatamente anterior a la presencia romana en la zona. No es descabellado pensar que la rápida colmatación de éste último sea una consecuencia directa de la ocupación romana. Con el desarrollo de los trabajos que se continuarán en esta zona de los fosos, así como el desmontaje de algunas de las estructuras excavadas que se sobreponen, se podrán esclarecer algunas hipótesis sobre las que se dispone la nueva fase de excavaciones. 


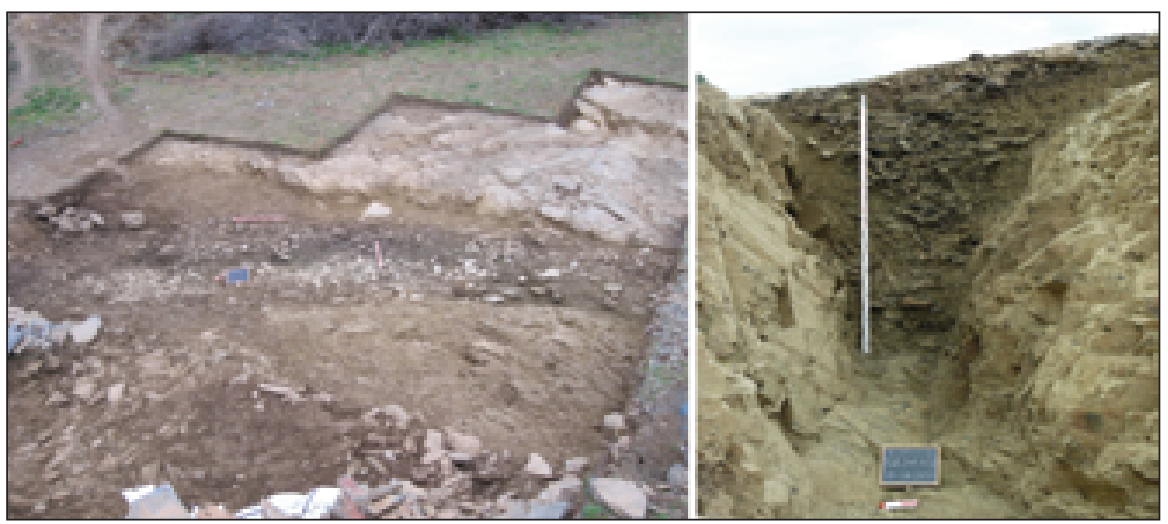

Figura 18.- Detalle de la colmatación asociada al Foso 2. Perfil estratigráfico 4, observándose la línea de corte provocada por la abertura del Foso 2, y depósito que se cerró posteriormente, sobre niveles sedimentarios asociados al Foso 3.

\section{Las plaquetas de piedra con grabados}

Portugal, a pesar de su pequeño tamaño, es uno de los países con mayor densidad de vestigios de arte figurativo prehistórico (Gomes 2002: 139). Las gentes que ocuparon el territorio dejaron su huella en numerosos soportes y contextos muy diferentes, algo que, por otro lado, nunca deja de sorprendernos. Este es el caso de las plaquetas de piedra grabadas del Castelinho, que ascienden en el momento de elaboración del presente artículo a más de 150, dato que lleva el estudio del arte figurativo de la Edad del Hierro a nuevos paradigmas que no habían sido planteados hasta el momento.

El arte de la Edad del Hierro en Portugal está poco y mal documentado. Los estudios sistemáticos son escasos y, cuando aparecen, su marcado carácter regional apenas consigue mostrar una parte de la dimensión del fenómeno (Baptista 1983, 1983-84, 1986, Santos 2003, Figueiredo 2008). A modo de ejemplo podemos mencionar el conocido caso del valle del Côa, cuyo arte de la Edad del Hierro representa el segundo momento más importante dentro del gran ciclo artístico de esta región (Baptista 1999; Luís 2005). De acuerdo con las tesis de Luís $(2009,2010)$ encontramos, a lo largo del valle de Côa, identificadas y atribuidas a la Edad del Hierro más de trescientas rocas, de las que apenas conocemos, hasta la fecha, el dibujo de ocho de ellas, y un conjunto de dibujos y fotografías de motivos sueltos de otras siete. En contraste con ese gran número de rocas localizadas, los contextos de ocupación del valle del Côa relativos a este período nos son prácticamente desconocidos (Luís 2005: 43).

Incidiendo específicamente en las lajas o plaquetas de arte mueble de este momento, conocemos hasta la fecha tres casos. El primero es el poblado inglés de Kilton Thrope donde se menciona una úni- ca laja con varios grabados de motivos geométricos, que formaría parte de un bloque de mayor tamaño colocado en posición vertical (Vyner 2007). Más cercano tenemos el caso de Aldeia Nova/Olival dos Telhões - Almendra, en Vila Nova de Foz Côa, una estación de época tardo-romana de donde procede una laja grabada que por los motivos representados y la técnica utilizada fue relacionada con la Edad del Hierro (Cosme 2008). Sin embargo, el caso más parecido al nuestro procede de Galicia, del castro de Formigueiros, donde fueron halladas seis lajas de esquisto que formaban parte del pavimento de una pequeña plaza situada entre las casas excavadas. Estas lajas estaban decoradas con diferentes motivos: combinaciones circulares de diferentes morfologías, caballos y peces. Los investigadores refieren estos grabados como las primeras representaciones de este tipo en un contexto arqueológico claro (Meijide y otros 2009).

Los trabajos arqueológicos que se vienen realizando en el Castelinho pueden deparar nuevos hallazgos, de ahí la provisionalidad de este primer estudio sobre el arte del castro. En el protocolo de recogida y documentación hemos abordado distintas variables, teniendo en cuenta en primer lugar las condiciones de hallazgo y los contextos asociados, diferenciando entre restos documentados en superficie, en las mismas terreras y durante el proceso de excavación. La documentación se realizó teniendo en cuenta el Sector o Cuadrante, la Unidad Estratigráfica y las coordenadas de hallazgo. Seguidamente abordamos el análisis morfológico de la superficie de las lajas y una primera aproximación a la tipología de los grabados.

Es importante mencionar que de las 147 plaquetas de piedra con grabados recogidas, 110 provienen del Foso 2. Aunque fueron depositadas de manera arbitraria, parece evidente que debieron cumplir 
con anterioridad alguna función que por ahora nos es desconocida. Explorar las posiciones y funcionalidad original de las lajas decoradas será una de nuestras tareas prioritarias. Por eso, tiene una especial importancia documentar las dimensiones de estas piezas, el área grabada y el tratamiento superficial, dado que estos factores nos podrían ofrecer algunos indicios de su localización original. Aunque fueron depositadas intencionalmente no siguen ningún patrón aparente. Por ejemplo, varios fragmentos que se hallaban distantes casaban entre sí (Lajas 14 y 37).

Hasta el momento, fuera del Foso 2 sólo se han localizado siete lajas que formaban parte de las estructuras del poblado (Lajas 1, 5, 11, 12), de los niveles de derrumbe del torreón Norte (Laja 6) e in- cluso de la misma muralla (Lajas 7 y 10). En el caso de estas últimas, la Laja 10 da la impresión de haber sido grabada después de su inserción en la estructura. En cuanto a las lajas que integran las estructuras, tenemos dos casos destacados: la Laja 1, que parece tratarse de un reaprovechamiento, y la Laja 5, cuyo grabado parece haber sido realizado a propósito para el lugar que ocupa en la construcción. Los motivos geométricos de la Laja 1 (Fig. 19), la primera en ser descubierta, están superpuestos: el reticulado que ocupa toda la superficie se superpone a los motivos figurativos (figuras humanas armadas, caballos y un jabalí). Estas observaciones nos llevan a elaborar la hipótesis de encontrarnos ante diferentes fases, hipótesis que tendrá que ser confirmada en la nueva fase de excavación del Castelinho.
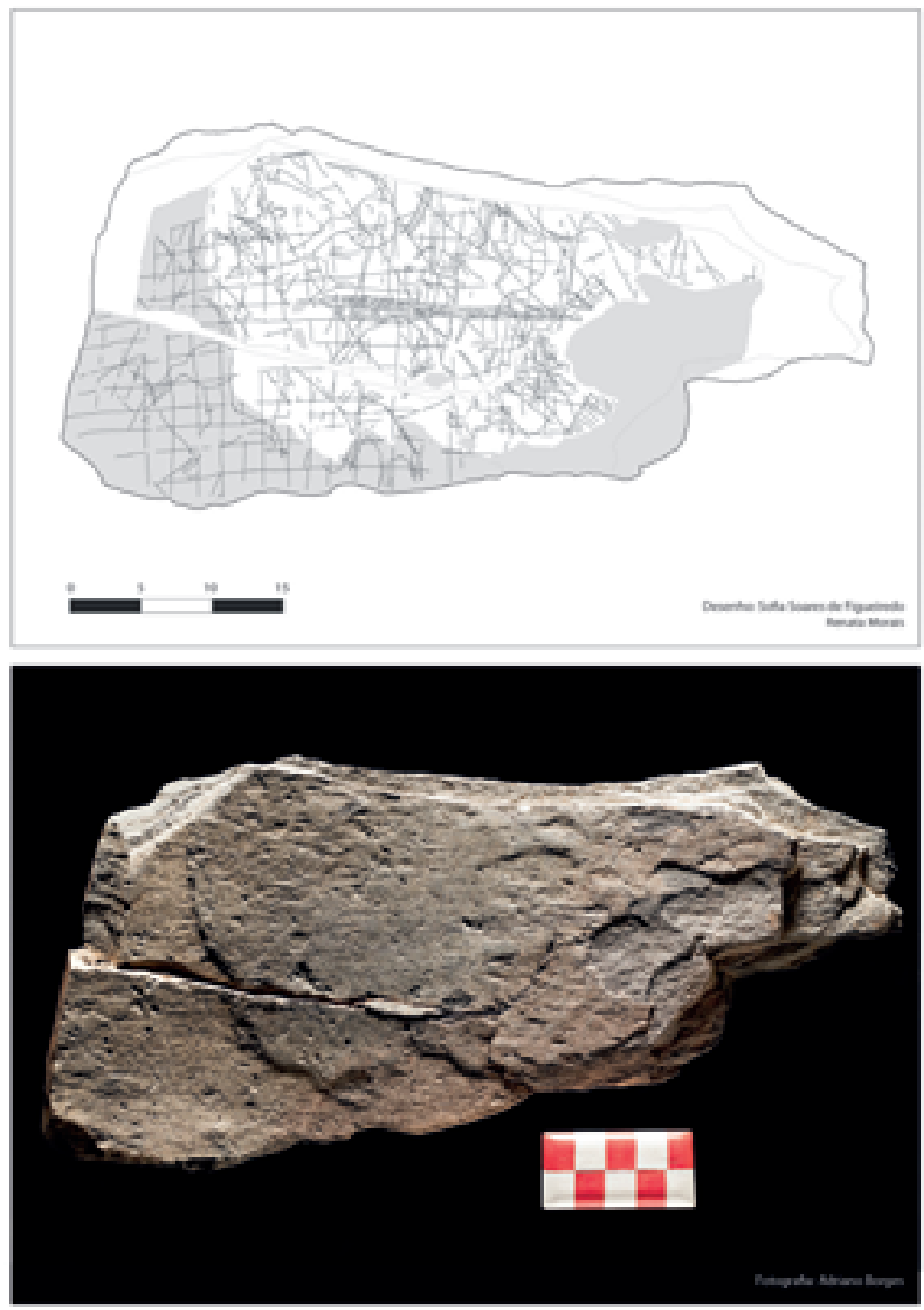

Figura 19.- Laja 1, la primera en ser localizada, mostrando bajo la retícula posibles escenas de caza, con antropomorfos portando armas, jabalíes y caballos. 


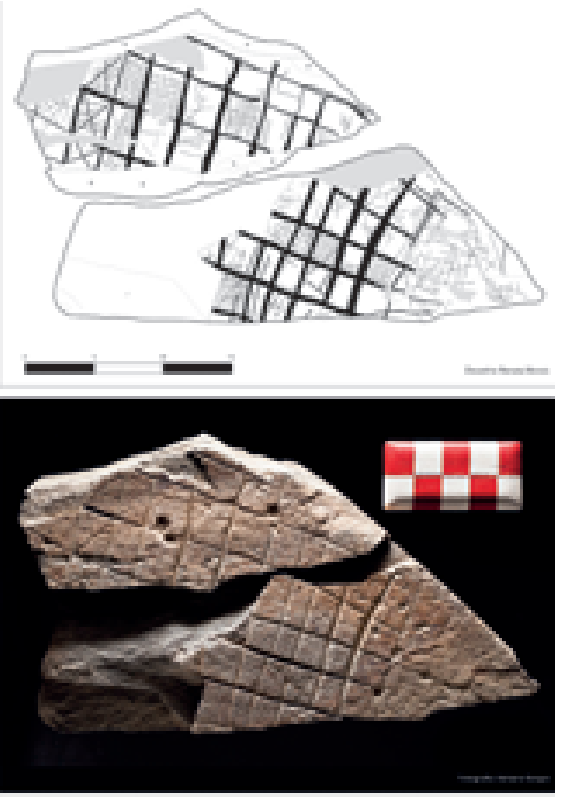

Figura 20.- Laja 2 y 2 A, con uno de los grabados más profundos, representando un reticulado grande y complejo segmentado en el interior.

Respecto a las dimensiones de las lajas, éstas varían entre 10 y $104 \mathrm{~cm}$ de longitud, y entre 6 y 45 $\mathrm{cm}$ de ancho. De esta forma se constata una gran variabilidad en las dimensiones, lo que estaría relacionado con las fracturas de las propias plaquetas. La técnica usada en los grabados, a semejanza del arte de la Edad del Hierro conocido en el valle del Côa, se restringe casi exclusivamente a la incisión filiforme, definida por un trazo muy fino y continuo, elaborado por medio de puntas de "sílex, cuarzo o hierro" (Baptista 1983-84: 76; apud Luís 2008: 419). Los principales motivos representados son los geométricos, donde los reticulados adquieren especial relevancia (Fig. 20), así como los motivos abstractos. Las grafías que mejor caracterizan este arte son las representaciones antropomorfas, zoomorfas y las armas. Las representaciones antropomorfas personifican generalmente guerreros y caballeros que pueden ir acompañados o no de armas. En su mayoría, estos personajes son representados de perfil; otras veces hallamos figuraciones singulares que recuerdan a sapos, con brazos en posición de orante (Fig. 21). Entre los zoomorfos, son los caballos los animales más representados. También aparecen pájaros, cérvidos y, al menos, dos jabalís; éstos últimos inéditos en los grabados conocidos de este período pero no dentro de las esculturas. Especialmente llamativa es una laja con epígrafe que parece corresponder a una inscripción con caracteres latinos ${ }^{4}$.

Los datos que hasta el momento tenemos del área excavada en Castelinho revelan un esfuerzo humano considerable en un espacio de reducidas dimensiones. Creemos que la excepcionalidad de los restos documentados es suficiente para dar una noticia preliminar y rápida del hallazgo, y ello a pesar de la provisionalidad de los datos y de tratarse de un asentamiento todavía en fase de excavación. Sin duda, el futuro análisis iconográfico y morfológico de las plaquetas será clave en la comprensión del imaginario de las poblaciones que habitaron el valle del río Sabor en el transcurso de la Edad del Hierro.
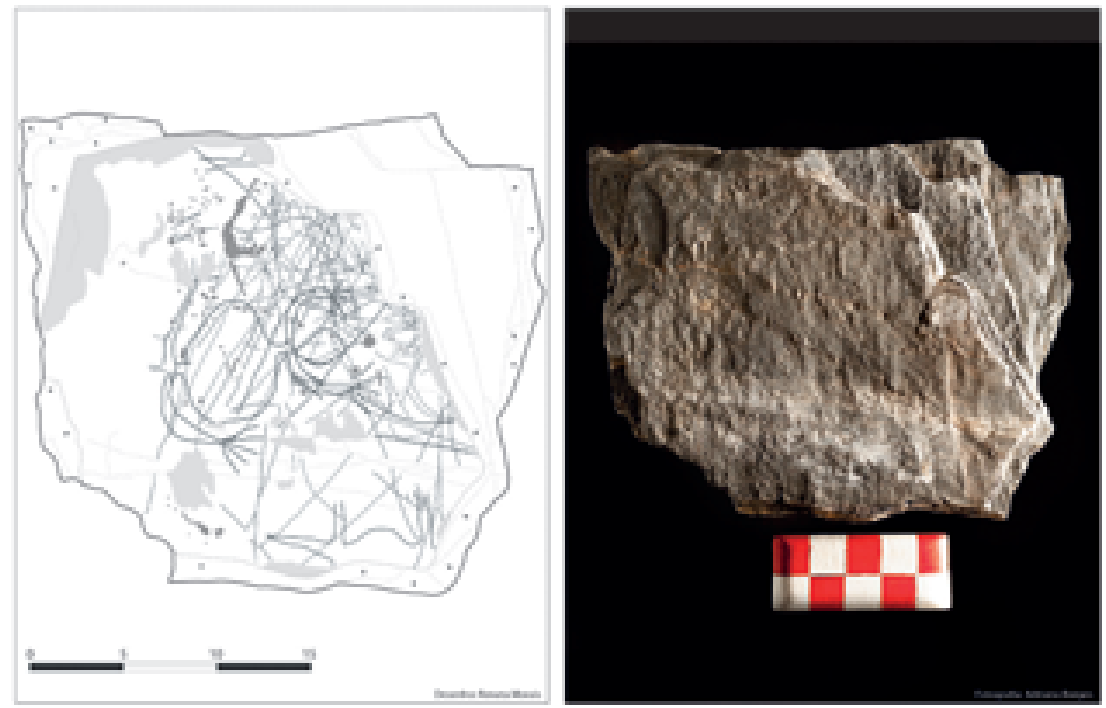

Figura 21.- Placa con figura de difícil adscripción tipológica, con los brazos en posición de orante. 


\section{Agradecimientos}

Nos gustaría agradecer su inestimable ayuda a todas aquellas personas que han colaborado con nosotros en el desarrollo de estos trabajos, comenzando por los coordinadores de las diferentes áreas: Paulo Dordio, Rita Gaspar, Sergio Pereira, Lourenço Rosa y Sergio Antunes; además del responsable del laboratorio y conservación de materiales André Tereso; del equipo de topografía con Jõao Nicolau; también a todo el equipo de Arte Rupestre por sus dibujos, fotografías y trabajos de campo, compuesto por Renata Morais, Dário Neves, José Maciel, Luis Carvalho, Marisa Silva y Adriano Borges. A Andrew May por su traducción al inglés; y especialmente a los profesores Gonzalo Ruiz Zapatero, Jesús Álvarez Sanchís, Teresa Chapa Brunet, Ángel Esparza Arroyo, Antonio P. Dinis, Amílcar Guerra, Teresa Soeiro, Armando Coelho, João Muralha y José Ruivo.

\section{Notas}

1. Los autores quieren mostrar su agradecimiento a EDP - Entidad Promotora del AHBS -, así como a Baixo Sabor ACE - Consórcio Construtor: Oderbrecht, Bento Pedroso Construções S.A. y Lena Construções -, la oportunidad que nos conceden para la publicación de este artículo.

2. Esta información fue corroborada por los Profesores Teresa Chapa, Gonzalo Ruiz Zapatero y Jesús Álvarez Sanchís, de la Universidad Complutense de Madrid, y por el Profesor Ángel Esparza Arroyo, de la Universidad de Salamanca, especialistas en este período que pudieron ver algunos de los materiales procedentes de esta primera fase de excavaciones.

3. Queremos expresar nuestro agradecimento al Dr. José Ruivo (Museu Monográfico de Conímbriga) por las informaciones que nos proporcionó relativas a este elemento.

4. Información dada por el Profesor Amílcar Guerra a quien agradecemos su colaboración.

\section{REFERENCIAS BIBLIOGRÁFICAS}

Baptista, A.M. (1983): O complexo de gravuras rupestres do Vale da Casa - (Vila Nova de Foz Côa). Arqueologia, 8: 57-69.

Baptista, A. M. (1984-1984): Arte rupestre no Norte de Portugal: Uma perspectiva. Portugália, nova série, IV-V: 71-82.

Baptista, A.M. (1999): No tempo sem tempo. A arte dos caçadores paleolíticos do Vale do Côa. Ed. PAVC, Vila Nova de Foz Côa.

Baptista, A. M. (1986): Arte rupestre pós-glaciária. Esquematismo e abstracção. História da Arte em Portugal. Do Paleolitico à Arte Visigótica, Publicações Alfa, Lisboa: 30-55.

Bonnaud, C. (2005): Les castros vettons et leurs populations au Second Âge du Fer (Ve siècle - II siècle avant J.C.). I : implantation et systèmes défensifs. Revista Portuguesa de Arqueologia, Volumen, 8, Número 1.

CAchero, F. J. L. (2008): Necrópolis de incineración y arquitectura funeraria en el noreste de la Península Ibérica durante el Bronce Final y la Primera Edad del Hierro. Complutum, 19 (1): 139-171.

Collis, J. (2010): Why do we still dig Iron Age ramparts? Murus celticus. Architecture et functions des ramparts de l'Âge du Fer (S. Fichtl, ed.), Actes du Colloque organisé par l'UMR 7044 de Strasbourg, l'UMR 6173-CITERES de Tours et Bibracte, à Glux-en-Glenne les 11 et 12 octobre 2006, Glux-en-Glenne, Bibracte: 27-35.

Cosme, S. R. (2008): Proto-história e Romanização entre o Côa e o Águeda. III Congresso de Arqueologia, Trásos-Montes, Alto Douro e Beira Interior: Proto-história e Romanização-Guerreiros e Colonizadores, 3: 72-80.

Cotter, C. (2003): The Cultural Background of Irish Forts with chevaux de frise. Chevaux-de-frise i fortificació en la primera edat del ferro europea (N. Alonso, E. Junyent, A. Lafuente, J. B. López, coords.), Universitat de Lleida, Lleida: 101-118.

Esparza Arroyo, A. (1988): La Edad del Hierro en Zamora. Actas del I Congreso de Historia de Zamora, T.2., Zamora: 101-126.

Esparza Arroyo, Á. (2003): Castros con piedras hincadas del oeste de la Meseta y sus aledaños. Chevaux-de-frise i fortificació en la primera edat del ferro europea (N. Alonso, E. Junyent, A. Lafuente, J. B. López, coords.), Universitat de Lleida, Lleida: 155-178.

Esparza Arroyo, Á. (2011): Los castros del oeste de la Meseta. Aldeas y ciudades en el primer milenio a. C. La Meseta Norte y los orígenes del urbanismo (J. Álvarez-Sanchís, A. Jimeno, G. Ruiz Zapatero, eds.), Complutum, 22 (2): 11-47. 
Figueiredo, S. S. (2008): As gravuras rupestres do concelho de Macedo de Cavaleiros. Fórum Valorização e Promoção do Património Regional. Actas das sessões. Do Paleolítico à Contemporaneidade, 3: $42-61$.

Gomes, M. V. (2002). Arte rupestre em Portugal - perspectiva sobre o último século. Arqueologia 2000. Balanço de um século de Investigação Arqueológica em Portugal. Arqueologia e História, 54: 139-194.

HiLl, J. D. (1995a): Ritual and Rubbish in the Iron Age of Wessex. British Archaeological Reports, British Series, 242, Oxford.

HiLl, J.D. (1995b): How should we study Iron Age societies and hillforts? A contextual study from southern England. Different Iron Ages: studies on the Iron Age in temperate Europe (J.D. Hill, C.G. Cumberpatch, eds.), British Archaeological Report S602, Oxford: 45-66.

Hock, M.; Coelho, L. (1977): O Castro de S. Juzenda em Vale de Prados, Mirandela (Nota Preliminar). O Arqueólogo Português, serie 3.a, vol. 7-9: 203-208.

Luís, L. (2005): Arte Rupestre e Ocupação Humana no Vale do Côa. Balanço da Investigação do Parque Arqueológico do Vale do Côa. Côavisão, 7, Vila Nova de Foz Côa: 31-60.

Luís, L. (2008): Em busca dos cavaleiros com cabeça de pássaro: Perspectivas de investigação da proto-história no Vale do Côa. Arte Prehistórico al aire libre en el Sur de Europa (R. de Balbín Behrmann, ed.), Junta de Castilla y León: 415-438.

Luís, L. (2009): "Per petras et per signos": A arte rupestre do Vale do Côa enquanto construtora do espaço na Proto-história. Lusitanos y vettones: Los pueblos prerromanos en la actual demarcación Beira Baixa - Alto Alentejo (P. Sanabria, ed.), Memorias 9, Museo de Cáceres: 213-240

Luís, L. (2010): A construção do espaço numa sociedade proto-histórica: A arte rupestre do Vale do Côa. Espaços e Paisagens Antiguidade Clássica e Heranças Contemporâneas, Vol. 3, História, Arqueologia e Arte, Coimbra: 53-67.

Matos, J. (2008): Fundamentos de Informação Geográfica. $5^{\circ}$ Edição Actualizada e Aumentada, LIDEL.

Meijide Cameselle, G., Vilaseco Vázquez, X. I., BlaszczyK, J. (2009): Lousas decoradas com círculos, cabalos e peixes do Castro de Formigueiros (Samos, Lugo). Gallaecia, 28: 113-130.

Ponte, S. (2006): Corpus Signorum das Fíbulas Proto-históricas e Romanas de Portugal. Caleidoscópio.

Ralston, I. (2006): Celtic Fortifications. Tempus, Stroud.

Redentor, A. (2000): Povoados Fortificados com Pedras Fincadas em Trás-Os-Montes. Conimbriga, XXXIX: 5-51.

Rodrigues, M.; Rebanda, N. (1995): Cerâmicas medievais do Baldoeiro (Adeganha - Torre de Moncorvo. Jornadas de Cerâmica Medieval e Pós-Medieval. C. M. Tondela, Tondela: 51-66.

Ruiz Zapatero, G. (2003): Las Fortificaciones de la Primera Edad del Hierro en la Europa Templada. Chevauxde-frise i fortificació en la primera edat del ferro europea (N. Alonso, E. Junyent, A. Lafuente, J. B. López, coords.), Universitat de Lleida, Lleida: 13-34.

Salido Domínguez, P.J. (2003-2004): La documentación literária aplicada al Registo Arqueológico: Las técnicas de construcción de los graneros romanos rurales". Espacio, Tiempo y Forma, Serie I, Prehistoria y Arqueología, 16-17: 463-478.

SAnches, M. J. (2003): Crasto de Palheiros - Murça. Reflexão sobre as condições de estudo e de interpretação duma mega-arquitectura pré-histórica no Norte de Portugal. Recintos Murados da Pré-história Recente (S. Jorge, coord.), DCTP/FLUP, Porto/Coimbra: 115-148.

Sande Lemos, F (1993): Povoamento romano de Trás-os-Montes Oriental. Universidade do Minho, Braga.

SAntos, F.J.C.; LAdRA, L. (2011): A cabeça antropomorfa do Castelinho. Um novo elemento de plástica antiga em Trás-os-Montes. Os celtas na Europa Atlântica, III Congresso Internacional sobre a cultura Celta. Instituto Galego do Estudos Celtigos, Narón.

SAntos, A. T. (2003). Uma abordagem hermenêutica-fenomenológica à arte rupestre da Beira Alta. O caso do Fial (Tondela, Viseu). Dissertação de mestrado defendida na Universidade do Porto, policopiada, Porto.

Silva, A.C.F. (1986): A Cultura Castreja no Noroeste de Portugal. Museu Municipal da Citânia de Sanfins, Paços de Ferreira.

Vyner, B. (2007): Rock-art in Cleveland and north-east Yorkshire: contexts and chronology. Art as a Metaphor: The prehistoric Rock-Art of Britain (A.D. Mazel, G. Nash, C. Waddington, eds.), British Archaeological Reports, Archaeopress, Oxford: 91-110. 